\section{Research Article}

(C) 2021 Martins et.al..

This is an open access article licensed under the Creative Commons Attribution-NonCommercial 4.o International License

(https://creativecommons.org/licenses/by-nc/4.o/)

Received: 13 October 2020 / Accepted: 12 December 2020/ Published: 17 January 2021

\title{
Interdependencies between COVID-19, Mental Illness and Living Uneasiness
}

\author{
José Garrucho Martins \\ Interdisciplinary Centre of Social Sciences - CICS.NOVA, Portugal \\ Carlos Miguel Ferreira \\ Interdisciplinary Centre of Social Sciences - CICS.NOVA, Portugal
}

\section{Sandro Serpa}

\begin{abstract}
Department of Sociology, Faculty of Social and Human Sciences, University of the Azores; Interdisciplinary Centre of Social Sciences - CICS.UAc/CICS.NOVA. UAc; Interdisciplinary Centre for Childhood and Adolescence - NICA - UAc, Portugal
\end{abstract}

DOI: https://doi.org/10.36941/ajis-2021-ooo1

\begin{abstract}
The spread of the COVID-19 pandemic has led to a profound change in the daily practices and symbolic representations of individuals, with strong social, economic and political implications, which no one is immune to. This article seeks to understand how a pandemic, specifically COVID-19, can generate or potentiate different forms of mental illness and living uneasiness. Thus, the aim is to know the varied manifestations of psychological suffering, from mild psychiatric disorders to the most intrusive ones, not forgetting the forms of widespread suffering which the pandemic causes and which are not reduced to the categories defined by the process of psychiatry. The relationships between mental illness, living uneasiness and COVID-19 are complex and multidimensional.
\end{abstract}

Keywords: Pandemic, COVID-19, mental illness, living uneasiness

\section{Introduction}

This article seeks to understand how a pandemic, COVID-19, can generate or potentiate different forms of mental illness and living uneasiness. In other words, the aim is to know the various manifestations of psychic suffering, from mild psychiatric disorders to the most intrusive ones, not forgetting the forms of widespread suffering that the pandemic causes and which are not reduced to the categories of psychiatry.

The analysis will attempt to reconcile the sociological perspectives that present social factors as causing illness with readings that favour social reaction. The links between mental illness, living conditions and COVID-19 are complex and multidimensional. However, the literature suggests that there is a negative correlation between COVID-19 and mental health status. Furthermore, COVID-19 
determines some changes in the processes of social integration and regulation.

The methodology adopted in this article is of an intensive type. It is about understanding the multiplicity of dimensions that shape the different forms of mental illness and living uneasiness within the context of the COVID-19 pandemic crisis.

The article is structured as follows: next section presents the literature review carried out on the topic under analysis, followed by the section describing the methods used. Subsequently, the results and their discussion are put forth. The article closes with the conclusion section.

\section{Literature Review}

It is not a matter of affirming some form of sociological imperialism in the face of data, categories, classifications of the biomedical sciences and this other discipline - psychiatry -, which, in some respects, is more controversial than the others in the same disciplinary area. In medicalisation, in the broad sense, and in psychiatry, the great power of social control lies on the fact that medicine has the authority to define behaviour, people and things. If medicalisation does not take place at the level of the definition of reality, medical social control loses its legitimacy and becomes more difficult to attain (Conrad \& Schneider, 1980).

There are controversies, and the consensus is fragile regarding the ascription of a clinical, psychopathological category to some social behaviours. It is important to remember that psychiatric diagnosis is made with problematic indicators in different senses: how they are interpreted, collected and selected. Michel Foucault, with some controversial humour, said somewhere that psychopathology was one of the most ideological disciplines. Avoiding some of these challenges, while drawing conclusions from them, this analytical work is both modest and ambitious. It is modest because it is based only on the studies of our fellow researchers, psychiatrists and clinical psychologists, in which they find the existence of significant, causal relationships of COVID-19 with various psychopathological disorders. It is ambitious because, based on the explanations that these specialists offer for the existence of this correlation - which they find in the knowledge already accrued in their disciplines -, sociologists may find other explanations, which complement those already provided by Psychiatry and Psychology.

The mobilisation of the theoretical and empirical contributions of authors defined as classical is relevant because they express a privileged status in contemporary sociological analysis, that is, they have classical status in sociological theory. This privileged position entails that, in the work of sociologists, this deference is made without prior demonstration and it is tacitly accepted because, by being classic, the work establishes criteria of significance in a disciplinary space. Classics reduce complexity, simplify and facilitate theoretical discussion (Alexander, 1987).

The mobilisation and integration of the theoretical and empirical positions of the classics and other systems of sociological thought shape the development of the medium-range theories proposed by Merton (Merton, 1970; Serpa, Ferreira, \& Diogo, 2020). These theories are not separated, but rather consolidated, within broader networks of theories (Merton, 1970). This approach suggests the intermediate position of this type of theory in a continuum between two poles: general theories and specific research projects; and global knowledge and local knowledge. It may help Sociology to move forward on two recurring issues: the relationship between the general and the singular, from the point of view of the scope of theories; and the relationship between the descriptive and the explanatory, from the point of view of the intelligibility of facts (Silva, 2013).

Sociology contributes to the understanding of the COVID-19 pandemic, as a social phenomenon, in its relationships with mental illness by working on issues such as "social order and crises; social inequalities in health; social construction of epidemic and contagious diseases; social space of health and collective management of disease and contagion; public health policies; social distance and confinement; science and scientific controversies" (Ferreira, Sá, Martins, \& Serpa, 2020, p. 14). The term "mental illness" is used as a synonym for "psychiatric illness", to avoid taking a position on the "mind/body" dualism (Garrucho Martins, 2020, p. 90), although the authors are aware that none of the 
different names is neutral (Garrucho Martins, 2020). The analysis will attempt to reconcile the sociological perspectives "that present social factors as causing illness" with "readings that favour social reaction” (Garrucho Martins, 2020, p. 83).

The knowledge accrued by the social sciences (Ferreira et al., 2020) is mobilised to understand how COVID-19 generated and/or aggravated the manifestation of "mental illness". The effects of the pandemic on mental health are largely the effects of public health policies, the guidelines for the management of daily life; they are mandatory rules, some of them with legal status. They are rules that determine how one should live in relationship with others and that non-compliance is a crime. Others are optional; the sanction for not accepting "counselling" is essentially moral, seeking to impose moral conformism, the mandatory nature of group pressure.

\section{Methods}

The methodology adopted in this article is of an intensive type. It is about understanding the multiplicity of dimensions that shape the different forms of mental illness and living uneasiness within the context of the COVID-19 pandemic crisis.

Qualitative literature document analysis was the favoured technique in this research. The type of documentary sources includes biomedical and psychological journals, manuals, academic theses and articles produced in the medical and the social sciences fields, which, by expressing different positions and interests in the medical, welfare, political and societal arenas, were important to understanding the construction of the discursive space on the social configuration of mental illness in the context of the COVID-19 pandemic crisis. The valuation of the article as an empirical field of analysis results from considering that it is the central formal means of the process of scientific production and communication, reporting on the scientific activity of scientists, where argumentative strategies of persuasion are developed and interpretative principles privileged by the authors and legitimised by peers are presented.

In these documents, cognition policies are shaped and manifested: language is used to build an "official" reality often around classifications that produce the promotion or marginalisation of ideas, and current concepts that selectively define situations and shape the readers' preferences, perceptions and cognition. These documents may be considered as places of symbolic struggles for the perception of the social world. These symbolic struggles can take on two different forms. The objective form shapes the possibility of acting through individual or collective actions of representation, aimed at showing and promoting certain realities. The subjective form shapes the possibility of acting by trying to change the categories of perception and appreciation of the social world, the cognitive and evaluative structures: the categories of perception and the systems of classification, that is, the words and the names that build social reality as much as they express it (Carvalho, 200o; Ramos, 1981).

As mentioned above, the data analysed - on the relationship between COVID-19 and mental illness - are part of preliminary investigations by researchers legitimised by biomedical sciences, clinical psychologists and psychiatrists. Criticism of these findings, concerning generous epistemological vigilance, calls for initial attention on how these data have been constructed. This is rather pertinent, inasmuch that the investigations are preliminary and the data is provisional. In the articles consulted and cited, there is a confidence in the "data", in a kind of naïve but over-emphasising empiricism, a product of disciplines whose history allows them not to have to justify themselves scientifically on all occasions and in relation to all procedures. They present themselves as if an epistemological cut had been made, once and for all, in an act and founding moment of the discipline. For this reason, simplistic positivism has been manifested, shown and demonstrated by the ease with which the results can be generalised based on samples that are intended to be representative, but in which it is not sufficiently explicit how they were constructed. Too focused in the testing procedures, of which the use of statistical techniques is an example, they do not question the pertinence of their use in the samples they use, causing, by this use, effects of scientificity and scientific artefacts. The use of these studies, which are a database for this research, has, however, these limitations. 


\section{Results and Discussion}

The social dimensions, in their relationships with mental illness, are both a causal and a selective element. The prescriptions that define them determine the objective and subjective aspects of social relationships. Like its counterparts in the past, the COVID-19 pandemic re-updates the most archaic and negative ghosts - in the sense ascribed by psychoanalysts. Ghosts or fantasies, as Laplanche and Pontalis (1970) comment, are "daydreams, scenes, episodes, novels, fictions, which the individual forges and tells himself in the waking state" (p. 230). Collective behaviour at the time of this pandemic seems to repeat a typology presented by mentality historians in their studies on the great epidemics in different historical periods. One such scholar, Delumeau (1989), on the subject of the plague, speaks of widespread fear and its disruptive consequences for individual and group relationships. To compare these behaviours with the contemporary ones, we will carry out an inventory of some of the elements of this typology.

For the contemporaries of the plague, it impressed "the instantaneity of the attack of evil and the fact that, rich or poor, young or old, no one could boast of escaping it" and "the insistence on speed emerges in all accounts" (Delumeau, 1989, p. 114). The perception of the first reactions of individuals and public policies to COVID-19 becomes intelligible as to the form of what has already been seen: "when the danger of contagion emerges, one initially tries not to see it" (Table 1).

Table 1. Some implications of the Covid-19 Pandemic

\begin{tabular}{|l|}
\hline Implications: \\
\hline Disruption of the social order \\
\hline Different collective behaviour \\
\hline New normality \\
\hline Psychic economy \\
\hline Normative internalisation of official requirements \\
\hline New self-control \\
\hline Maintenance of physical distance \\
\hline Social stressor \\
\hline Limitations on the intensity of social relationships \\
\hline $\begin{array}{l}\text { Prevalence of some psychiatric disorders, with differences depending on the social position, } \\
\text { age and gender of individuals }\end{array}$ \\
\hline
\end{tabular}

Source: Authors' production

The chronicles of the plague highlight the authorities' frequent neglect in taking the measures imposed by the imminent danger, but it is true that, once the defence mechanism was set in motion, the means of protection were perfected in the course of the century (Delumeau, 1989, p. 117). We cannot fail to remember confinement and quarantine in the following description:

[...] all the chronicles of the plague insist on the interruption of trade and handicrafts, on the closure of shops, even of churches, on the suspension of all entertainment, on the emptiness of streets and squares [...] cut off from the rest of the world, the inhabitants distance themselves from each other in the very interior of the cursed city, fearing to contaminate each other. They avoid opening the windows of their houses and going out. People struggle to resist locked in their homes, with the reserves they have been able to accumulate. If it is necessary to go out to buy what is necessary, people have to take precautions. Customers and sellers of basic needs only greet each other from a distance and put between them the space of a large counter (Delumeau, 1989, pp. 121 and 122).

The fear that the physical distance would not be kept was so great that "[...] in Milan, in 1630, some only venture into the street armed with a gun, thanks to which they keep at a distance anyone 
likely to be contagious" (Delumeau, 1989, p. 122). Collective behaviour ranged from stoicism to derangement, from discouragement to madness.

The links between mental illness, living conditions and COVID-19 are complex and multidimensional (Chang \& Park, 2020; Li \& Wang, 2020; Fan \& Nie, 2020; Ru, 2020; Holmes et al., 2020; Nwachukwu et al., 2020; Zhao et al., 2020; Sigurvinsdottir, Thorisdottir, \& Gylfason, 2020; Sauer, Jungmann, \& Witthöft, 2020; Daigle \& Rudnick, 2020). However, "A large body of literature suggests that there is a negative correlation between COVID-19 and mental health status" (Fan \& Nie, 2020, p. 1). COVID-19 determines some changes in the processes of social integration and regulation. Different countries at different times have implemented specific and, sometimes, clearly differentiated measures. However, and almost generally speaking, confinement, quarantine, lockdown, physical distance and hygiene rules, as normative guidelines, require constant attention to oneself and to the relationships with the other, which interferes with social regulation and integration - two dimensions of socialisation - that are explicitly called into question; requiring, to different degrees - depending on the social belonging of individuals - a re-socialisation work.

The Durkheim study on suicide (1982) mentions the importance of these issues. By recalling this sociologist's proposal, we can understand "mental illness" as a kind of "flaw" in social integration and regulation (we state this without wishing to pay tribute to any explanatory facility that sees in these relationships some form of mechanical action of cause and effect) that calls into question logical and moral conformism. Mental illness, such as suicide, in our theoretical proposal, manifests itself differently, depending on the intensity of regulation and integration: very weak social regulation; excessive social regulation; very strong social integration; and very weak social integration. COVID-19 asks for and requires that we rearrange these intensities. Thinking in this way about the effects of COVID-19 may allow us, in future work, to test the relationships between regulation/integration and different psychiatric pathologies, as Durkheim (1982) demonstrated in his study on suicide: very weak social integration and selfish suicide; very strong social integration and altruistic suicide; very weak social regulation and anomalous suicide; excessive social regulation as an enabler of fatalistic suicide.

The pandemic interferes with the quantity and quality of social effervescence (Durkheim, 1991), causing an analogous heresy in the religious that society is, in the relationship of the individual with society, as a relationship of the profane with the sacred, of the faithful with their God (society).

The normative guidelines for living in a pandemic period relate to social interaction as a social order to be preserved; individuals have to respect rules and rites, be committed, show normality that is acknowledged by others, establishing new normality. As Durkheim (1982), already mentioned in this regard, and Goffman $(1968,1973 a, 1973 b, 1974,1975)$ remind us, this requirement is total, fragile and precarious.

To live in a pandemic period, each individual is also required to work on his or her mental economy, to internalise the prescriptions of official bodies (e.g., World Health Organisation or national entities), to pay permanent attention to himself or herself not to forget what is required, and to have self-control of emotions (Elias, 1989, 1990, 2010).

Public policies to control the consequences of the pandemic (quarantine, confinement, physical distance and hygiene practices, among others), such as population management/control practices - in the sense of Foucault's bio-politics - have effects on mental health.

These policies affect the individuals' experiences in the different social worlds that they are part of and "induce many psychiatric individual and collective problems such as panic, anxiety, depression, post-traumatic stress disorders" (Jakovljevic, Bjedov, Jaksic, \& Jakovjlevic, 2020, p. 6). The meta-analysis of the review of studies on the effects of the pandemic, in its relationships with mental illness, has demonstrated the existence of an increase in the prevalence of some psychiatric disorders, albeit with differences, depending on the individuals' job and gender (González-Sanguino et al., 2020).

The spread of the COVID-19 pandemic has led to a profound shift in the daily habits and representations of individuals themselves, with strong social, economic and political implications, which no one is immune to (Grabowski, Meldgaard, \& Hulvej Rod, 2020). The COVID-19 pandemic interferes, with higher or lower acuteness, with more or less negative and disruptive consequences, in 
the daily lives of individuals and differs according to the differences of their social conditions (Sá \& Serpa, 2020). The different objective dimensions of social integration, for example, partly determine both the objective and subjective responses to the representations - in the three-fold sense, psychological, gnoseological and dramaturgical - and to the public policies of pandemic management/control. They explain, in part, as reasons - causes and motives -, how new and different orientations are generated for the relationship with oneself and with others, in a period of social "abnormality", perceived as such because the unquestionable, part of a moral and logical conformism is explicitly called into question, which institutionally (we recall Durkheim, in his definition of "institution") requires other behaviours.

COVID-19 can be understood as a social stressor that interferes with social integration and regulation. The concept of "social stressor" allows understanding how negative, persistent and perceived uncontrollable conditions may become the facilitating backdrop for the manifestation of psychological disturbances. It is also important "[...] as a tool of analysis, as long as one is aware of its limitations and as long as the role of context - psychological, social, cultural and economic - is always included when trying to understand why an individual or a group considers a certain situation to be stressful, while others do not" (Helman, 2003, p. 263, cit. in Garrucho Martins, 2020, p. 88). A pandemic is a life event, considered stressful, which contributes to the disease, the emergence of different mental disorders, with greater or lesser disruptive intensity, and modes of the suffering of living, whether pathological or not. It accentuates periods of crisis in the trajectory of diseases of those who already experience mental illness and facilitates its manifestation in those who are more predisposed to it.

The limitations of the flows and intensity of social relationships - work, leisure, school -, combined with the restrictive constraints of family and institutional/public support, have negative effects on mental health. The characteristics of these dynamics are pivotal for mental health/illness. As Horwitz (2002) states, "[...] major sociological tradition relates to characteristics of interpersonal networks to the production of distress. Work in this tradition derives states of mental health from characteristics of role relationships rather than from individual qualities" (pp. 159-160). Changes in labour relationships, increased precariousness and unemployment, and work at home with children due to the closure of schools, restrictions on social relationships, limitations on the access to support services, the closure of clubs and associations and the prohibition of social group activities are elements of pressure on families, which may result in "distress, mental health problems and violence" (Fegert, Vitiello, Plener, \& Clemens, 2020, p. 2) between parents and children, and spouses. Work, for example, as an element of social integration, contributes to mental health, while unemployment and precariousness are factors that encourage mental and psychological illness, which is one of the ways that living uneasiness manifests itself. The effects of precariousness and unemployment are most negative for individuals with fewer economic resources, women, and single mothers (Lennon \& Limonic, 2006).

The impact of quarantine on mental health manifests itself in increased depression, "[...] low mood, irritability, insomnia, anger and emotional exhaustion" (Lennon \& Limonic, 2006, p. 4). There seems to be a scientific consensus about these relationships, according to specialists in biomedical disciplines. According to Loades et al. (2020),

Quarantine in adults generally has negative psychological effects including confusion, anger, and posttraumatic distress. Duration of quarantine, infection fears, boredom, frustration, lack of necessary supplies, lack of information, financial loss, and stigma appear to increase the risk of psychological outcomes. Social distancing and school closures may therefore increase mental health problems in children and adolescents, already at higher risk of developing mental health problems compared to adults at a time when they are also experiencing anxiety over a health threat and threats to family employment/income (p. 2).

Some authors find in the confinement and the subsequent period the possibility of the manifestation of more severe disorders from a psychopathological point of view. Besides anxiety, posttraumatic stress disorder, depression and suicidal behaviours, addictive behaviours, eating disorders 
and domestic violence, "[...] a vast literature relates social isolation and hallucinations" (Mengin et al., 2020, p. 544).

Changes in sociability, intensity, connectivity, and density of the composition of social networks determine - or, at least, greatly condition - living uneasiness and psychiatric disorders (Xiao, Zhang, Kong, Li, \& Yang, 2020).

In addition to all the restrictive guidelines and the requirement to learn new forms of sociability, there are new rules which are similar to the behaviour that characterises some pathologies. It is like that for all orientations, a kind of rules of civility, which have similarities and update in the patients with certain ritualised behaviours and obsessive-compulsive practices. Freud already defined obsessive acts as a "[...] neurotic ceremonial in small manners, additions, restrictions and arrangements put into practice, always in the same way or with regular modifications, in the execution of certain acts of daily life" (Freud, 1983, p. 215). The individual feels that he or she is required to perform these acts because any "[...] infraction of the ceremonial is punished with intolerable anguish that forces him or her to correct and execute it literally" (Freud, 1983, p. 215). The requirement to wash one's hands frequently and to maintain physical distance in relationships with others is similar, from a purely expressive point of view, to an obsessive-compulsive disorder and, in patients with this pathology, enables the recurrence and maintenance of symptoms (Fontenelle \& Miguel, 2020).

The requirement to maintain physical distance is not harmless to mental health. We know from scholars of the proxemics that spatial distances are critical regulators for social life. Spatial distances are learned, contributing to the construction of "situational personalities", "[...] whose simplest form is linked to our behaviour in the course of different types of intimate, personal, social and public relationships" (Hall, 1986, p. 135). The anthropologist Edward T. Hall, one of the pioneers of these studies, spoke of these relationships as distances, stating that "[...] the perception of space is dynamic because it is related to action - what can be done in a given space - rather than what is seen by passive viewing" (Hall, 1986, p. 135). This symbiotic relationship of action with space is a product of incorporated and internalised learning, which can be thought of in unusual moments and situations, but which is largely pre-reflexive.

These ritualised rules, as Goffman (1973a, 1973b) points out, structure relationships in public. By being modified, there is interference not only in the relationship between us and others but also with what in us, in many moments and situations, was unquestionable. It is, therefore, with no surprise that we see that mentally ill individuals manifest specific relationships with the dynamics of action/space, and the distances considered "normal" remain, to a certain extent, suspended. Unpredictability and new norms seem to try to emerge, hence the feeling of strangeness towards their interlocutors, which may, in more extreme situations, lead to conditions of stigmatisation (Ferreira et al., 2020; Gualano, Lo Moro, Voglino, Bert, \& Siliquini, 2020), as the situation of the individual who is unable to fully accept social acceptance by manifesting or considering as such, one or more characteristics that do not correspond to what is deemed normal in a given social order (Goffman, 1975).

The normative guidelines for greetings explained as rules of protection against contagion (such as the ban of kissing and shaking hands), written with quasi-status in state law, are manuals of civility for living in a pandemic; they force individuals to control their emotions and demand other ways of managing it (Elias, 1989, 1990). The pressure that the attention ascribed to oneself to comply with new rules and transform them into rituals, the movements of body and spirit, as if making one aware of the internalisation of exteriority and the externalisation of interiority, causes anxiety, that feeling of imminent danger of a failed act - in the double sense of Goffman's and Freud's theories.

\section{Conclusion}

This article sought to understand how a pandemic, specifically COVID-19, can generate or potentiate different forms of mental illness and living uneasiness. Thus, the purpose of the study was to know the various manifestations of psychic suffering, from mild psychiatric disorders to the most intrusive ones, including the forms of widespread suffering that the pandemic causes and which are not reduced to 
the categories of psychiatry.

The disruptive logics of a pandemic such as COVID-19 have effects on mental health. Studies already available confirm that this pandemic situation enables the emergence of mental illness, reinforces the symptoms of the disease in individuals already diagnosed, and increases the modalities of mental suffering in the form of living uneasiness. The effects of COVID-19 manifest themselves and potentiate various psychiatric disturbances, depending on the predispositions of individuals, which are related to their social insertions.

The management of the pandemic - both individual and collective - more or less sharply interferes with this belief in a kind of pre-established harmony that living in society entails. Regulation and social integration are two aspects of socialisation, of the production of moral and logical conformism, as Durkheim (1982) pointed out. By interfering in these dimensions, COVID-19 is forcing the work of re-socialisation. This tension between what individuals were and what they are asked/required to be is an enabler of disease and unease: living with oneself, as a way of living with oneself as if one were another, and living with others, requires another management:

"Societies are measured in part in relation to how they rise to the occasion of collective crises and learn from them. [...].These challenges may require special attention after the pandemic to facilitate mental well-being and functioning of people who are identified as having - or being at high risk of havingpandemic-related mental problems after the pandemic" (Rudnick, 2020, pp. 1-2).

\section{Acknowledgements}

Funding: University of Azores, Interdisciplinary Centre of Social SciencesCICS.UAc/CICS.NOVA.UAc, UID/SOC/04647/2020, with the financial support of FCT/MEC through national funds and when applicable co-financed by FEDER under the PT2020 Partnership Agreement.

\section{References}

Alexander, J. (1987). The centrality of the classics. In A. Giddens, \& J. Turner (Eds.), Social theory today (pp. 11-57). Stanford: Stanford University Press.

Carvalho, L. M. (200o). Nós através da escrita: Revistas, especialistas e conhecimento pedagógico (1920-1936) [Us through writing: Magazines, specialists and pedagogical knowledge (1920-1936)]. Cadernos Prestige, 3. Lisboa: Educa.

Chang, M. C., \& Park, D. (2020). Incidence of post-traumatic stress disorder after coronavirus disease. Healthcare, 8(4), 373. https://doi.org/10.3390/healthcare8040373

Conrad, P., \& Schneider, J. (1980). Deviance and medicalization: From badness to sickness. St. Louis: Mosby.

Cui, L.-B., Wang, X.-H., \& Wang, H.-N. (2020). Mental health during and after the COVID-19 emergency in Italy. Letters to the Editor - Psychiatry and Clinical Neurosciences.

Daigle, P., \& Rudnick, A. (2020). Shifting to remotely delivered mental health care: Quality improvement in the COVID-19 pandemic. Psychiatry International, 1(1), 31-35. https://doi.org/10.3390/psychiatryint1010005

Delumeau, J. (1989). History of fear in the West 1300-180o. São Paulo: Companhia das Letras.

Durkheim, E. (1982). Suicide - Sociological study. Lisboa: Editorial Presença.

Durkheim, E. (1991). Elementary forms of religious life. Paris: Le Livre de Poche.

Elias, N. (1989). The civilisational process. $1^{\text {st }}$ Vol. Lisboa: Publicações Dom Quixote.

Elias, N. (1990). The civilisational process. $2^{\text {nd }}$ Vol. Lisboa: Publicações Dom Quixote.

Elias, N. (2010). Beyond Freud - Sociology, psychology, psychoanalysis. Paris: Éditions La Découvert.

Fan, H., \& Nie, X. (2020). Impacts of layoffs and government assistance on mental health during COVID-19: An evidence-based study of the United States. Sustainability, 12(18), 7763. https://doi.org/10.3390/su12187763

Fegert, J. M., Vitello, B., Plener, P. L., \& Clemens, V. (2020). Challenges and burden of the coronavirus 2019 (COVID19) pandemic for child and adolescent mental health: A narrative review to highlight clinical and research needs in the acute phase and the long return to normality. Child and Adolescent Psychiatry and Mental Health, 14, 20. https://doi.org/10.1186/s13034-020-00329-3

Ferreira, C. M., Sá, M. J., Martins, J. G., \& Serpa, S. (2020). The COVID-19 contagion-pandemic dyad: A view from social sciences. Societies, 10(4), 77. https://doi.org/10.3390/soc10040077 
Fontenelle, L. F., \& Miguel, E. C. (2020). The impact of COVID-19 in the diagnosis and treatment of obsessivecompulsive disorder. Depress Anxiety, 37(6), 510-511. https://doi.org/10.1002/da.23037

Freud, S. (1983). Obsessive acts and religious practices. In S. Freud, Scheme of psychoanalysis and other writings of psychoanalytic doctrine. Madrid: Alianza Editorial.

Garrucho Martins, J. (2020). Nights and days - How to live with bipolar disorder. Vila Nova de Gaia: Creative Strategies.

Goffman, E. (1968). Asylums. Studies on the social condition of mental illness. Paris: Les Éditions de Minuit.

Goffman, E. (1973a). The staging of everyday life - 1. Self-presentation. Paris: Les Éditions de Minuit.

Goffman, E. (1973b). The staging of everyday life - 2. Relations in public. Paris: Les Éditions de Minuit.

Goffman, E. (1974). The rites of interaction. Paris: Les Éditions de Minuit.

Goffman, E. (1975). Stigma. The social uses of disability. Paris: Les Éditions de Minuit.

González- Sanguino, C., Ausín, B., Castellanos, M. A., Saiz, J., López-Gómez, A., Ugidos, C., \& Muñoz, M. (2020). Mental health consequences during the initial stage of 2020 Coronavirus pandemic (COVID-19) in Spain. Brain, Behavior, and Immunity, 87, 172-176. https://doi.org/10.1016/j.bbi.2020.05.040

Grabowski, D., Meldgaard, J., \& Hulvej Rod, M. (2020). Altered self-observations, unclear risk perceptions and changes in relational everyday life: A qualitative study of psychosocial life with diabetes during the COVID19 lockdown. Societies, 10(3), 63. https://doi.org/10.339o/soc10030063

Gualano, M. R., Lo Moro, G., Voglino, G., Bert, F., \& Siliquini, R. (2020). Effects of Covid-19 lockdown on mental health and sleep disturbances in Italy. International Journal of Environmental Research and Public Health, 17(13), 4779. https://doi.org/10.339o/ijerph17134779

Hall, E. T. (1986). The hidden dimension. Lisboa: Relógio d'Água.

Holmes, E. A., O’Connor, R. C., Perry, V. H., Tracey, I., Wessely, S., Arseneault, L., ... Bullmore, E. (2020). Multidisciplinary research priorities for the COVID-19 pandemic: A call for action for mental health science. The Lancet Psychiatry, 7(6), 547-56o. https://doi.org/10.1016/S2215-0366(20)30168-1

Horwitz, A. V. (2002). Creating mental illness. Chicago: The University of Chicago Press.

Jakovljevic, M., Bjedov, S., Jaksic, N., \& Jakovljevic, I. (2020). COVID-19 pandemia and public and global mental health from the perspective of global health security. Psychiatria Danubina, 32(1), 6-14. https://doi.org/10.24869/psyd.2020.6

Laplanche, J., \& Pontalis, J.-B. (1970). Vocabulary of psychoanalysis. Lisboa: Moraes Editores.

Lennon, M. C., \& Limonic, L. (2006). Work and unemployment as stressors. In A. V. Horwitz, \& T. L. Scheid (Eds.), A handbook for the study of mental health - Social contexts, theories, and systems (pp. 213-225). New York: Cambridge University Press.

Li, L. Z., \& Wang, S. (2020). Prevalence and predictors of general psychiatric disorders and loneliness during COVID19 in the United Kingdom. Psychiatry Research, 113267. https://doi.org/10.1016/j.psychres.2020.113267

Loades, M. E., Chaltbun, E., Higson-Sweeney, N., Reynolds, S., Shafran, R., Brigden, A. ... Crawley, A. (2020). Rapid systematic review: The impact of social isolation and loneliness of mental health of children and adolescents in the context of COVID-19. Journal of the American Academy of Child E Adolescent Psychiatry, 59(11), 12181239. https://doi.org/10.1016/j.jaac.2020.05.009

Mengin, A., Allé, M. C., Rolling, J., Ligier, F., Schroder, C., Lalanne, L. ... Giersch, A. (202o). Psychopatological consequences of confinement. Encephale, 46(3S), S43-S52. https://doi.org/10.1016/j.encep.2020.04.007

Merton, R. K. (1970). Sociology: Theory and structure. São Paulo: Master Jou.

Nwachukwu, I., Nkire, N., Shalaby, R., Hrabok, M., Vuong, W., Gusnowski, A., ... Agyapong, V. I. O. (2020). COVID19 pandemic: Age-related differences in measures of stress, anxiety and depression in Canada. International Journal of Environmental Research and Public Health, 17(17), 6366. https://doi.org/10.339o/ijerph17176366

Ramos, A. G. (1981). The new science of organizations: A reconceptualization of the wealth of nations. Toronto: University of Toronto Press.

$\mathrm{Ru}$, Y. (2020). A sociological analysis of mental health under COVID-19. SSRN. https://dx.doi.org/10.2139/ssrn.3644838

Rudnick, A. (2020). Social, psychological, and philosophical reflections on pandemics and beyond. Societies, 10(2), 42. https://doi.org/10.339o/soc10020042

Sá, M. J., \& Serpa, S. (2020). The global crisis brought about by SARS-CoV-2 and its impacts on education: An overview of the Portuguese panorama. Science Insights Education Frontiers, 5(2), 525-530. http://dx.doi.org/10.15354/sief.20.aro39

Sauer, K. S., Jungmann, S. M., \& Witthöft, M. (2020). Emotional and behavioral consequences of the COVID-19 pandemic: The role of health anxiety, intolerance of uncertainty, and distress (in)tolerance. International Journal of Environmental Research and Public Health, 17(19), 7241. https://doi.org/10.339o/ijerph17197241 
Serpa, S., Ferreira, C. M., \& Diogo, F. (2020). Specialization or fragmentation of sociology: Scientific, academic, and professional challenges. The International Journal of Interdisciplinary Social and Community Studies 15(2), 1532. https://doi.org/10.18848/2324-7576/CGP/v15io2/15-32

Sigurvinsdottir, R., Thorisdottir, I. E., \& Gylfason, H. F. (2020). The impact of COVID-19 on mental health: The role of locus on control and internet use. International Journal of Environmental Research and Public Health, 17(19), 6985. https://doi.org/10.339o/ijerphi7196985

Silva, A. (2013). Processos no tempo: Uma reflexão sobre o valor que a história acrescenta à sociologia, a partir do magistério de Vitorino Magalhães Godinho [Processes in time: A reflection on the value that history adds to sociology, from the teaching of Vitorino Magalhães Godinho]. Forum Sociológico, 23. https://doi.org/10.40oo/sociologico.848

Xiao, H., Zhang, Y., Kong, D., Li, S., \& Yang, N. (2020). Social capital and sleep quality in individuals who self-isolated for 14 days during the coronavirus disease 2019 (COVID-19) outbreak in January 2020 in China. Medical Science Monitor, 26, e923921-1-e923921-8. https://doi.org/10.12659/MSM.923921

Zhao, S. Z., Wong, J. Y. H., Wu, Y., Choi, E. P. H., Wang, M. P., \& Lam, T. H. (2020). Social distancing compliance under COVID-19 pandemic and mental health impacts: A population-based study. International Journal of Environmental Research and Public Health, 17(18), 6692. https://doi.org/10.339o/ijerph17186692 